\title{
A Review of Machine Translation Systems in India and different Translation Evaluation Methodologies
}

\author{
Aditi Kalyani \\ PhD Scholar \\ Sardar Patel University \\ Vallabh Vidhyanagar, India
}

\author{
Priti S. Sajja, Ph.D \\ Professor \\ G.H. Patel P.G. Department of Computer Science \\ and Technology \\ Vallabh Vidhyanagar, India
}

\begin{abstract}
Despite the linguistic diversity, communication is important for economic and social growth. But it is impossible for a human being to know all languages. This led to the inception of machine translation. Machine Translation (MT) is a field of Artificial Intelligence and Natural Language Processing which deals with translation from one language to another using machine translation system. Even after translation, in order to assess the goodness of MT system i.e. if the translated output is of human translation quality or not, some Evaluation strategy is required. This paper gives a review of the work done on various Indian machine translation systems and existing methods for evaluating the translated MT system's Output.
\end{abstract}

\section{General Terms}

Machine Translation, Natural Language Processing.

\section{Keywords}

Computational Linguistics, Morphology

\section{INTRODUCTION}

India is home to not just one or two languages but to a myriad number of diverse lingual families. Mainly the languages belong to two chief families - Indo Aryan and Dravidian. These are spoken by more than $90 \%$ of Indian population. Apart from these two, Austro-Asiatic languages and TibetoBurman linguistic languages also give key contribution to the language list.

More than 30 languages and approximately 2000 dialects are used for communication in India, amongst which Hindi and English are taken as languages for official work. There are 22 scheduled languages for different states which include Assamese, Bengali, Bodo, Dogri, Gujarati, Hindi, Malayalam, Manipuri, Marathi, Nepali, Oriya, Punjabi, Sanskrit, Kannada, Kashmiri, Konkani, Maithili, Santali, Sindhi, Tamil, Telugu, and Urdu. ${ }^{[1]}$

It is difficult for a human being to know all these languages and hence the need for a translator arises, where the translation from one language to another is done. Manual translation of these language pairs is a very cumbersome task and thus we opt for the automatic machine translation systems, wherein computer software translates one natural language to another which the human understands.

The history of machine translation dates back to July 1949 when Warren Weaver (a director at the Rockefeller Foundation, New York) wrote an influential paper which introduced Americans to the idea of using computers for translation. The first conference on MT came in 1952. There was the first demonstration of a translation system in January 1954 , and it attracted a great deal of attention and since then there has been no stopping. The field of Machine Translation has been expanding limitlessly in all countries including India.

Machine translation is useful in many places where: 1) Highly repetitive content is present 2) Content is similar to translation memories but not exactly the same 3) High value content that is changing every hour and every day and there is time sensitivity 4)Content does not need to be perfect but just approximately understandable. And many other areas.

\section{APPROACHES OF MACHINE}

\section{TRANSLATORS}

Many technical approaches have been developed to solve the challenges of language translation. Some of these approaches include:

\subsection{Rule Based Machine Translation (RBMT)}

Commonly known as "Knowledge-Based Machine Translation, is based on linguistic information about source and target languages. RBMT systems are basically constituted by two components: the rules that account for the syntactic knowledge, and the lexicon, which deals with the morphological, syntactic, and semantic information of the language. ${ }^{[2]}$ These retrieved from dictionaries and grammars of each language. RBMT system translates input sentence (in source language) to output sentences (in some target language) on the basis of rules and lexicons of both the source and the target languages involved in translation. There are three different types of rule-based machine translation systems:

\subsubsection{Direct Systems}

The Dictionary Based Machine Translation maps output and input using basic rules.

\subsubsection{Transfer based RBMT Systems}

The Transfer Based Machine Translation uses syntactic and morphological features of language (lexicons).

\subsubsection{Interlingual RBMT Systems}

Here source language is transformed into an intermediate language which is independent of any of the languages involved in the translation. This intermediate representation is known as Interlingua, which can be transformed into multiple languages. ${ }^{[3][4]}$ 


\subsection{Example Based Machine Translation (EBMT)}

This approach uses a bilingual corpus for translating one language to another. EBMT matches the sequence of words with words in corpus by decomposing the complete sentence into fragments and matching these fragments against proper examples in the corpus. It uses analogy translation principle.

The performance of this method depends on the corpus. The key things about corpus include size of the corpus (number of samples in corpus), quality of corpus and also if the corpus is supervised, unsupervised or semi-supervised.

\subsection{Statistical Machine Translation (SMT)}

Warren Weaver in 1949 introduced the idea of Statistical Machine Translation. In SMT, translations are generated on the basis of statistical models whose parameters are derived from the analysis of bilingual text corpora.

Statistical machine translation (SMT) is an approach to MT that is characterized by the use of machine learning methods.
This means that we apply a learning algorithm to a large body of previously translated text, known variously as a parallel corpus, parallel text, bitext, or multitext. ${ }^{[6]}$

\subsection{Hybrid Machine Translation System}

Statistical and rule-based MT complements each other. One overcomes shortcomings of the other, with their very different strengths and weaknesses. An optimized MT architecture should include elements of both theories. Hence the Hybrid Machine Translation System comes into picture.

Hybridization of machine translation architectures can be done using various methods: 1) Hybridization guided by RBMT 2) Hybridization guided by corpus-based MT.

\section{INDIAN MACHINE TRANSLATION SYSTEMS}

The table below introduces existing MT systems in India based on different translation Approaches (explained in earlier section) along with the year of release, key people involved, language pair and details regarding the system:

Table 1. Indian Machine Translation Systems

\begin{tabular}{|c|c|c|c|c|c|c|}
\hline$\#$ & $\begin{array}{c}\text { Translation } \\
\text { System }\end{array}$ & Year & $\begin{array}{c}\text { People } \\
\text { Responsible }\end{array}$ & $\begin{array}{c}\text { Source } \\
\text { Language }\end{array}$ & $\begin{array}{c}\text { Target } \\
\text { Language }\end{array}$ & Details \\
\hline A) & \multicolumn{6}{|c|}{ Direct Machine Translation Systems } \\
\hline 1. & $\begin{array}{l}\text { Anusaaraka } \\
\text { systems among } \\
\text { Indian Languages } \\
{[28][29]}\end{array}$ & 1995 & Rajeev Sangal & $\begin{array}{l}\text { Telugu, } \\
\text { Kannada, } \\
\text { Bengali, } \\
\text { Punjabi and } \\
\text { Marathi }\end{array}$ & Hindi & $\begin{array}{l}\text { The output of the system followed the grammar of } \\
\text { the source language only. Developed by IIT } \\
\text { Kanpur (earlier),IIIT Hyderabad(Now) }\end{array}$ \\
\hline 2. & $\begin{array}{l}\text { Punjabi to Hindi } \\
\text { MT System }\end{array}$ & $\begin{array}{l}2007 \\
2008\end{array}$ & $\begin{array}{l}\text { G S Josan and G } \\
\text { S Lehal }\end{array}$ & Punjabi & Hindi & $\begin{array}{l}\text { Based on direct word-to-word MT approach. } \\
\text { Accuracy of this system is } 90.67 \% \text {. } \\
\text { Developed by Punjabi University, Patiala. }\end{array}$ \\
\hline 3. & $\begin{array}{l}\text { Web based Hindi- } \\
\text { to-Punjabi MT } \\
\text { System }\end{array}$ & 2010 & $\begin{array}{l}\text { Goyal V and } \\
\text { Lehal G S }\end{array}$ & Hindi & Punjabi & $\begin{array}{l}\text { Extended version of Hindi-to-Punjabi MT System } \\
\text { to Web. } \\
\text { Developed by Punjabi University, Patiala. }\end{array}$ \\
\hline 4. & $\begin{array}{l}\text { Hindi-to-Punjabi } \\
\text { MT System } \\
{[12][32][33][34]}\end{array}$ & $\begin{array}{l}2009 \\
2011\end{array}$ & $\begin{array}{l}\text { Goyal V and } \\
\text { Lehal G S }\end{array}$ & Hindi & Punjabi & $\begin{array}{l}\text { The translation accuracy of the system is } 87.60 \% \\
\text { on the basis of accuracy test. } \\
\text { Developed by Punjabi University, Patiala. }\end{array}$ \\
\hline B) & \multicolumn{6}{|c|}{ Transfer-Based MT Systems } \\
\hline 1. & Mantra MT ${ }^{[14]}$ & 1997 & Bharati & English & Hindi & $\begin{array}{l}\text { Uses XTAG based super tagger and light } \\
\text { dependency analyzer for performing analysis of } \\
\text { the input English text. }\end{array}$ \\
\hline 2. & $\begin{array}{l}\text { MANTRA MT } \\
{[13][21]}\end{array}$ & 1999 & $\begin{array}{l}\text { Hemant Darbari } \\
\text { and Mahendra } \\
\text { Kumar Pandey }\end{array}$ & English & $\begin{array}{l}\text { Hindi, } \\
\text { Bengali, } \\
\text { Telugu, } \\
\text { Gujarati }\end{array}$ & $\begin{array}{l}\text { Translates in specific domain of personal } \\
\text { administration that includes gazette notifications, } \\
\text { office orders, office memorandums and circulars } \\
\text { Uses TAG and LTAG to represent English \& } \\
\text { Hindi grammar. It is based on synchronous Tree } \\
\text { Adjoining Grammar and uses tree transfer for } \\
\text { translating from English to Hindi. }\end{array}$ \\
\hline
\end{tabular}




\begin{tabular}{|c|c|c|c|c|c|c|}
\hline 3. & $\begin{array}{l}\text { An English-Hindi } \\
\text { Translation System } \\
{[15]}\end{array}$ & 2002 & $\begin{array}{l}\text { Gore } \mathrm{L} \text { and Patil } \\
\mathrm{N}\end{array}$ & English & English & $\begin{array}{l}\text { Uses different grammatical rules of source and } \\
\text { target languages and a bilingual dictionary for } \\
\text { translation. The domain of the system was } \\
\text { weather narration }\end{array}$ \\
\hline 4. & $\operatorname{MAT}^{[16]}$ & 2002 & Murthy K & English & Kannada & $\begin{array}{l}\text { Uses UCSG(Universal Clause Structure } \\
\text { Grammar), morphological analyser } \\
\text { \& post-editing }\end{array}$ \\
\hline 5. & Shakti ${ }^{[17]}$ & 2003 & $\begin{array}{l}\text { Bharati, R } \\
\text { Moona, P Reddy, } \\
\text { B Sankar, D M } \\
\text { Sharma and R } \\
\text { Sangal }\end{array}$ & English & $\begin{array}{l}\text { Indian } \\
\text { languages }\end{array}$ & $\begin{array}{l}\text { Combines linguistic rule-based approach with } \\
\text { statistical approach. The system consists of } 69 \\
\text { modules }\end{array}$ \\
\hline 6. & $\begin{array}{l}\text { English-Telugu MT } \\
\text { System }^{[18]}\end{array}$ & 2004 & $\begin{array}{l}\text { Bandyopadhyay } \\
\text { S }\end{array}$ & English & Telugu & $\begin{array}{l}\text { Uses dictionary containing } 42,000 \text { words. A word } \\
\text { form synthesizer for Telugu is developed and } \\
\text { incorporated in the system. }\end{array}$ \\
\hline 7. & $\begin{array}{l}\text { Telugu-Tamil MT } \\
\text { System }^{[18]}\end{array}$ & 2004 & $\begin{array}{l}\text { Bandyopadhyay } \\
\text { S }\end{array}$ & Telugu & Tamil & $\begin{array}{l}\text { Uses the Telugu Morphological analyser and } \\
\text { Tamil generator for translation. The system makes } \\
\text { use of Telugu-Tamil dictionary. } \\
\text { It also uses verb sense disambiguation. }\end{array}$ \\
\hline 8. & OMTrans $^{[35][36]}$ & 2004 & $\begin{array}{l}\text { Mohanty S, } \\
\text { Balabantaray R C }\end{array}$ & English & Oriya & $\begin{array}{l}\text { Based on grammar and semantics of the source } \\
\text { and target language. } \\
\text { Uses WSD too. }\end{array}$ \\
\hline 9. & $\begin{array}{l}\text { The MaTra } \\
\text { System }^{[34]}[37]\end{array}$ & $\begin{array}{l}2004 \\
2006\end{array}$ & $\begin{array}{l}\text { Ananthakrishnan } \\
\text { R, Kavitha M, } \\
\text { Hegde J J, } \\
\text { Chandra } \\
\text { Shekhar, Ritesh } \\
\text { Shah, Sawani } \\
\text { Bade, and } \\
\text { Sasikumar M }\end{array}$ & English & $\begin{array}{l}\text { Hindi, } \\
\text { Bengali, } \\
\text { Telugu, } \\
\text { Gujarati }\end{array}$ & $\begin{array}{l}\text { The domain of the system is news, annual reports } \\
\text { and technical phrases It has different dictionaries } \\
\text { for different domains. Requires considerable } \\
\text { human assistance in analyzing the input. Uses } \\
\text { sentence splitter. }\end{array}$ \\
\hline 10. & $\begin{array}{l}\text { English-Kannada } \\
\text { machine-aided } \\
\text { translation } \\
\text { system }^{[20][37]}\end{array}$ & 2009 & $\begin{array}{l}\text { K Narayana } \\
\text { Murthy }\end{array}$ & English & Kannada & $\begin{array}{l}\text { The domain is of government circulars. Uses } \\
\text { Universal Clause Structure Grammar (UCSG) } \\
\text { formalism. The system is funded by the Karnataka } \\
\text { government }\end{array}$ \\
\hline 11. & $\begin{array}{l}\text { Tamil-Hindi } \\
\text { Machine-Aided } \\
\text { Translation } \\
\text { system }^{[20][12]}\end{array}$ & 2009 & $\begin{array}{l}\text { Sobha L, } \\
\text { Pralayankar P } \\
\text { and Kavitha V, } \\
\text { Prof. C N } \\
\text { Krishnan }\end{array}$ & Tamil & Hindi & $\begin{array}{l}\text { Based on Anusaaraka. } \\
\text { Uses a lexical-level } \\
\text { translation and has } 80-85 \% \text { coverage }\end{array}$ \\
\hline 12. & $\begin{array}{l}\text { Sampark System: } \\
\text { Automated } \\
\text { Translation among } \\
\text { Indian } \\
\text { Languages }^{[19]}\end{array}$ & 2009 & & English & $\begin{array}{c}\text { Indian } \\
\text { Languages }\end{array}$ & $\begin{array}{l}\text { Uses Computational Paninian Grammar (CPG) for } \\
\text { analyzing language and combines it with machine } \\
\text { learning. } \\
\text { It is developed using both traditional rules-based } \\
\text { and dictionary-based algorithms with statistical } \\
\text { machine learning. }\end{array}$ \\
\hline C) & \multicolumn{6}{|c|}{ Interlingua Machine Translation Systems } \\
\hline 1. & $\begin{array}{l}\text { ANGLABHARTI } \\
{[20]}\end{array}$ & 2001 & $\begin{array}{l}\text { R M K Sinha, } \\
\text { Jain R, Jain A }\end{array}$ & English & $\begin{array}{c}\text { Indian } \\
\text { Languages }\end{array}$ & $\begin{array}{l}\text { Developed using pseudo-interlingua approach. } \\
\text { The domain of this system is public health }\end{array}$ \\
\hline 2. & $\begin{array}{l}\text { UNL-based } \\
\text { English-Hindi MT } \\
\text { System }^{[39][5]}\end{array}$ & 2001 & $\begin{array}{l}\text { Dave S, Parikh J } \\
\text { and } \\
\text { Bhattacharyya P }\end{array}$ & $\begin{array}{l}\text { English, } \\
\text { Hindi }\end{array}$ & $\begin{array}{l}\text { Hindi, } \\
\text { Bengali, } \\
\text { Marathi }\end{array}$ & $\begin{array}{l}\text { Uses Universal Networking } \\
\text { Language (UNL) as the Interlingua structure. } \\
\text { Developed by IIT Mumbai. }\end{array}$ \\
\hline
\end{tabular}




\begin{tabular}{|c|c|c|c|c|c|c|}
\hline 3. & AnglaHindi ${ }^{[40]}$ & 2003 & $\begin{array}{l}\text { R M K Sinha and } \\
\text { Jain A }\end{array}$ & English & $\begin{array}{l}\text { Indian } \\
\text { Languages }\end{array}$ & $\begin{array}{l}\text { Pseudo interlingual rule-based English to Hindi } \\
\text { Machine-Aided Translation System. }\end{array}$ \\
\hline D) & \multicolumn{6}{|c|}{ Hybrid Machine Translation Systems } \\
\hline 1. & $\begin{array}{l}\text { Anubharti } \\
\text { Technology }\end{array}$ & $\begin{array}{l}1995 \\
2004\end{array}$ & Sinha & Hindi & $\begin{array}{l}\text { Indian } \\
\text { Languages }\end{array}$ & $\begin{array}{l}\text { A combination of example-based, corpus-based } \\
\text { approaches and some elementary } \\
\text { grammatical analysis }\end{array}$ \\
\hline 2. & ANUBHARTI-II ${ }^{[39]}$ & 2004 & R M K Sinha & Hindi & $\begin{array}{l}\text { Indian } \\
\text { Languages }\end{array}$ & $\begin{array}{l}\text { Uses Generalized Example-Base (GEB) along } \\
\text { with Raw Example-Base (REB) MT approach for } \\
\text { hybridization }\end{array}$ \\
\hline 3. & $\begin{array}{l}\text { Bengali to Hindi } \\
\text { MT System }\end{array}$ & 2009 & $\begin{array}{l}\text { Chatterji S, Roy } \\
\text { D, Sarkar S and } \\
\text { Basu A }\end{array}$ & Bengali & Hindi & $\begin{array}{l}\text { Uses an integration of SMT with a lexical transfer } \\
\text { based system (RBMT) }\end{array}$ \\
\hline 4. & $\begin{array}{l}\text { Lattice Based } \\
\text { Lexical Transfer in } \\
\text { Bengali Hindi MT } \\
\text { Framework }^{[23]}\end{array}$ & 2011 & $\begin{array}{l}\text { Sanjay Chatterji, } \\
\text { Praveen Sonare, } \\
\text { Sudeshna Sarkar, } \\
\text { and Anupam } \\
\text { Basu }\end{array}$ & Bengali & Hindi & $\begin{array}{l}\text { Uses transfer based MT approach with the help of } \\
\text { lattice-based data structure }\end{array}$ \\
\hline E) & \multicolumn{6}{|c|}{ Example Based Machine Translation (EBMT) Systems } \\
\hline 1. & ANUBAAD $^{[24]}$ & $\begin{array}{l}2000 \\
2004\end{array}$ & $\begin{array}{l}\text { Bandyopadhyay } \\
\text { S }\end{array}$ & English & Bengali & $\begin{array}{l}\text { Domain specific to English Headlines translation } \\
\text { Example-base, Generalized Tagged example- base } \\
\text { and Phrasal example-base are separately } \\
\text { maintained } \\
\text { If the headline cannot be translated using above } \\
\text { methods then the heuristic translation strategy is } \\
\text { used }\end{array}$ \\
\hline 2. & $\begin{array}{l}\text { VAASAANUBAA } \\
\text { DA }^{[25]}\end{array}$ & 2002 & $\begin{array}{l}\text { Vijayanand K, } \\
\text { Choudhury S I } \\
\text { and Ratna P }\end{array}$ & Bengali & Assamese & $\begin{array}{l}\text { Domain limited to News Text } \\
\text { Sentence level Machine Translation for Bengali } \\
\text { Includes pre-processing and post-processing tasks. } \\
\text { Uses bilingual aligned corpus }\end{array}$ \\
\hline 3. & $\begin{array}{l}\text { Shiva and Shakti } \\
\text { MT System }\end{array}$ & 2003 & $\begin{array}{l}\text { CMU USA, IIIT } \\
\text { Hyderabad and } \\
\text { IISC Bangalore, } \\
\text { India }\end{array}$ & English & $\begin{array}{l}\text { Hindi, } \\
\text { Marathi and } \\
\text { Telugu }\end{array}$ & $\begin{array}{l}\text { Uses combination of Example-based, rule based } \\
\text { and statistical approaches. }\end{array}$ \\
\hline 4. & $\begin{array}{l}\text { ANGLABHARTI- } \\
\text { II }^{[20][39]}\end{array}$ & 2004 & R M K Sinha & English & $\begin{array}{l}\text { Indian } \\
\text { languages }\end{array}$ & $\begin{array}{l}\text { Uses Generalized example-base (GEB) approach } \\
\text { and Raw Example-Base (REB) } \\
\text { Contains the modules for an error analysis and } \\
\text { post-editing automaticaly. }\end{array}$ \\
\hline 5. & $\begin{array}{l}\text { Hinglish machine } \\
\text { translation } \\
\text { system }^{[26]}\end{array}$ & 2004 & Sinha and Thakur & Hindi & English & $\begin{array}{l}\text { Based on AnubBarti-II and AnglaBharti-II } \\
\text { Performs very shallow grammatical analysis }\end{array}$ \\
\hline 6. & $\begin{array}{l}\text { English to }\{\text { Hindi, } \\
\text { Kannada, Tamil }\} \\
\text { and Kannada to } \\
\text { Tamil Language- } \\
\text { Pair } \\
\text { Example Based MT } \\
\text { [20][39] }\end{array}$ & 2006 & $\begin{array}{l}\text { Balajapally P, } \\
\text { P Pydimarri, M } \\
\text { Ganapathiraju, N } \\
\text { Balakrishnan and } \\
\text { R Reedy }\end{array}$ & $\begin{array}{l}\text { English } \\
\text { Kannada }\end{array}$ & $\begin{array}{l}\text { Hindi, } \\
\text { Kannada and } \\
\text { Tamil } \\
\text { Tamil }\end{array}$ & $\begin{array}{l}\text { Based on a bilingual dictionary comprising of } \\
\text { sentence dictionary, phrases dictionary, words } \\
\text { dictionary and phonetic dictionary. }\end{array}$ \\
\hline
\end{tabular}




\begin{tabular}{|c|c|c|c|c|c|c|}
\hline 7. & $\begin{array}{l}\text { The MATREX } \\
\text { System }{ }^{[41][42]}\end{array}$ & 2008 & $\begin{array}{l}\text { Ankit Kumar } \\
\text { Srivastava, } \\
\text { Rejwanul Haque, } \\
\text { Sudip Kumar } \\
\text { Naskar and Andy } \\
\text { Way }\end{array}$ & English & Hindi & $\begin{array}{l}\text { Uses marker based chunking and "edit-distance } \\
\text { style" dynamic programming alignment algorithm } \\
\text { Domain limited to Conference papers }\end{array}$ \\
\hline F) & \multicolumn{6}{|c|}{ Statistical Machine Translation Systems } \\
\hline 1. & Shakti ${ }^{[39][20]}$ & 2003 & $\begin{array}{l}\text { Bharati, R } \\
\text { Moona, P Reddy, } \\
\text { B Sankar, D M } \\
\text { Sharma and R } \\
\text { Sangal }\end{array}$ & English & $\begin{array}{l}\text { Indian } \\
\text { language }\end{array}$ & $\begin{array}{l}\text { Combines linguistic rule based approach with } \\
\text { statistical approach }\end{array}$ \\
\hline 2. & $\begin{array}{l}\text { English to Indian } \\
\text { Languages } \\
\text { Machine } \\
\text { Translation } \\
\text { System } \\
\text { [27] }\end{array}$ & 2006 & $\begin{array}{l}\text { Consortium of } \\
\text { Nine institutions } \\
*\end{array}$ & English & $\begin{array}{l}\text { Indian } \\
\text { Languages }\end{array}$ & $\begin{array}{l}\text { Limited to Tourism and Healthcare domain } \\
\text { Uses statistical techniques and tools including the } \\
\text { POS tagger, parser, decoder }\end{array}$ \\
\hline
\end{tabular}

* C-DAC Mumbai, IISc Hyderabad, C-DAC Pune, IIT Mumbai, Jadavpur University Kolkatta, IIIT Allahbad, Utkal University

Bangalore, Amrita University Coimbatore and Banasthali Vidyapith Banasthali

\section{EVALUATION OF MACHINE TRANSLATION}

There are many systems in existence for translation but translation merely is not sufficient, it should be understandable, acceptable and must be of good quality. Hence, in order to judge the quality of translation, some evaluation measures are required.

The main aim of machine translation evaluation is to check that how well the machine's translated output correlates with human's reference translated output, for same language MT Evaluation strategies were initially proposed by Miller and Beeber-center in 1956 followed by Pfaffine in 1965. In the beginning MT evaluation was carried out only by human judges. This process, however, was time-consuming and highly subjective. Then as the field of machine Translation grew there arose the dire need for automation i.e., for fast, objective, and reusable methods of evaluation, the results of which are not biased or subjective at all. To this date, several metrics for automatic evaluation have been proposed and which are accepted by the MT community enthusiastically, but the research is never ending.

Automatic MT evaluation started with introduction of BLEU proposed by Paninani et al in 2001. Following IBM's metric (BLEU), DARPA designed NIST in 2002, Lavie and Denkowski proposed METEOR in 2005.

\subsection{Human Evaluation}

Manual evaluation is done by calculating fluency, adequacy and fidelity (Hovy, 1999; White and O'Connell, 1994). Adequacy is used to evaluate the quantity of the information existent in the original text that a translation contains. Commonly fluency refers to the degree to which the translation is well-formed according to the grammar of target language ${ }^{[8]}$. Fidelity refers to the amount of information retained in translated output in comparison to candidate.

In human evaluation there are two types of evaluators:
Bilingual, those who understand both source and target language and Monolingual i.e. understanding only target language.

Here, the human evaluator looks at the translation and judges it to check that if it is correct or not based upon factors described above. The score of human evaluator is given on a particular scale based on which the translations are ranked.

One of the most important peculiarity of human evaluation is that two human evaluators when judging the same text could give two different evaluations, as might the same evaluator at different moments (even for exact matches). Which means that human criteria for evaluation of Machine output is subjective. Also human evaluations are non-reusable, expensive and time consuming. To overcome these situations we need automatic system which can perform faster and give the output if not same but at least comparable to human output and can be reused over and over.

\subsection{Automatic Evaluation}

Human Evaluations are actually gold standards but the main issue in such evaluation is Cost and Time. Humans take more time and are expensive. Hence we need automatic metrics which are: 1.Quick 2.Inexpensive 3.Language-independent 4.Correlate highly with human evaluation 5. Have little marginal cost per run ${ }^{[9]}$.

Mostly all automatic metrics are based on either Edit Distance Based, Precision Based, Recall Based, F-measure based. The boom of automatic metric started with the introduction of BLEU (Papineni et al., 2001) which is based on average of matching n-grams between candidate and reference. ${ }^{[9]}$ Following IBM's lead NIST (Doddington, 2002) came out, which calculates matched n-grams of sentences and attach different weights to them. ${ }^{[10]}$ GTM (Turian et al., 2003) computes precision, recall and f-measure in terms of maximum unigram matches. In same year ROUGE (Lin and Hovy, 2003) was introduced that created the summary \& compared it with the summary created by human (Recall oriented). 2005 proved to be very important because one of the most successful metric METEOR (Banerjee \& Lavie, 2005) 
\{latest modification: 2012\} released. This was based on various modules (Exact Match, Stem Match, Synonym Match and POS Tagger). ${ }^{[7]}$ After this various other metrics came into existence and many versions of already existing metrics were also released. Some of the other metrics are:

- BLANC (Lita et al., 2005): Based on features of BLEU and ROUGE ${ }^{[43]}$

- TER (Snover et al., 2006): Metric for measuring mismatches $^{[44]}$

- ROSE (Song and Cohn, 2011): Uses syntactic resemblance (Here Part of Speech) ${ }^{[45]}$

- $\quad$ AMBER (Chen and Kuhn, 2011): Based on BLEU but adds recall, extra penalties, and some text processing variants ${ }^{[46]}$

- LEPOR (Han et al., 2012): Combines sentence length penalty and n-gram position difference penalty. Also uses precision and recall ${ }^{[47]}$

- PORT (Chen et al., 2012): Based on precision, recall, strict brevity penalty, strict redundancy penalty and an ordering measure. ${ }^{[48]}$

- METEOR Hindi (Ankush Gupta et al., 2010): A modified version of the METEOR containing features specific to Hindi ${ }^{[49]}$

In spite of existence of so many metrics there is no such metric which works such that it can correlate well with humans and can be used on all the languages (esp. free word order languages, morphologically rich languages and Resource poor languages).

\section{CONCLUSIONS}

In this paper we did a brief survey of existing Machine Translation Systems in India along with the approaches used for translation (i.e. rule-based, hybrid and statistical approaches). Not many resources are available for free word order languages, morphologically rich languages and Resource poor languages and most of the translators are domain specific which focus only on particular domain translations.

Also we discussed evaluation strategies for evaluating the translated output of machines. Many Human evaluation strategies have been applied and various automatic methods of evaluation (Metrics) have also been proposed off-late, to assess the quality of translation, but there is still no metric in existence which can perform remarkably well for all the languages at one time i.e. it is not comparable to human assessment. Hence MT is an open research field even today.

\section{REFERENCES}

[1] http://web.archive.org/web/20131029190612/http://censu sindia.gov.in/Census_Data_2001/Census_Data_Online/L anguage/Statement1.htm

[2] A.-L. Lagarda, V. Alabau, F. Casacuberta R. Silva, and E. D'1az-de-Liano, "Statistical Post-Editing of a RuleBased Machine Translation System $\square$ ", Proceedings of NAACL HLT, Boulder, Colorado, June 2009.

[3] Nirenburg, Sergei (1989). "Knowledge-Based Machine Translation". Machine Trandation 4 (1989), 5 - 24. Kluwer Academic Publishers. Retrieved 20 June 2012.
[4] Koehn, Philipp (2010). Statistical Machine Translation. Cambridge: Cambridge University Press. p. 15

[5] G V Garje and G K Kharate, "SURVEY OF MACHINE TRANSLATION SYSTEMS IN INDIA", International Journal on Natural Language Computing (IJNLC) Vol. 2, No.4, October 2013

[6] ADAM LOPEZ, "Statistical Machine Translation", ACM Computing Surveys, Vol. 40, No. 3, Article 8, August 2008.

[7] Satanjeev Banerjee and Alon Lavie (2005), "METEOR: An Automatic Metric for MT Evaluation with Improved Correlation with Human Judgments", Proceedings of the ACL 2005 Workshop on Intrinsic and Extrinsic Evaluation Measures for MT and/or Summarization.

[8] EuroMatrix, "Survey of Machine Translation Evaluation".

Available:www.euromatrix.net/deliverables/Euro matrix_D1.3_Revised.pdf.

[9] Kishore Papineni, Salim Roukos, Todd Ward, and WeiJing Zhu,"BLEU: A Method for Automatic Evaluation of Machine Translation"Proceedings of the 40th Annual Meeting of the Association for Computational Linguistics (ACL), Philadelphia,pp.311-318,July 2002.

[10] George Doddington, “Automatic Evaluation of Machine Translation Quality using N-gram Cooccurrence Statistics", Proceedings of 2nd HumanLanguage Technologies Conference (HLT-02). SanDiego, CA, pp 128-132. 2002.

[11] Akshar Bharati, Vineet Chaitanya, Rajeev Sangal, "COMPUTATIONAL LINGUISTICS IN INDIA: AN OVERVIEW".

[12] Sitender, Seema Bawa, "Survey of Indian Machine Translation Systems", International Journal of Computer Science And Technology, Vol. 3, Issue 1, Jan. - March 2012.

[13] Vishal Goyal \& Gurpreet Singh Lehal, (2010) "Web Based Hindi to Punjabi Machine Translation System", International Journal of Emerging Technologies in Web Intelligence, Vol. 2, no. 2, pp. 148-151, ACADEMY PUBLISHER.

[14] Sudip Naskar \& Shivaji Bandyopadhyay, (2005) "Use of Machine Translation in India: Current status"AAMT Journal, pp. 25-31.

[15] Lata Gore \& Nishigandha Patil, (2002) "English to Hindi - Translation System", In proceedings of Symposium on Translation Support Systems. IIT Kanpur. pp. 178-184.

[16] Murthy. K, (2002) "MAT: A Machine Assisted Translation System", In Proceedings of Symposium on Translation Support System( STRANS-2002), IIT Kanpur. pp. 134-139.

[17] Bharati, R. Moona, P. Reddy, B. Sankar, D.M. Sharma \& R. Sangal, (2003) "Machine Translation: The Shakti Approach", Pre-Conference Tutorial, ICON-2003.

[18] Parameswari K, Sreenivasulu N.V., Uma Maheshwar Rao G \& Christopher M, (2012) "Development of Telugu-Tamil Bidirectional Machine Translation System: A special focus on case divergence", in proceedings of 11th International Tamil Internet conference, pp 180-191 
[19] Sampark: Machine Translation System among Indian languages

http://tdildc.in/index.php?option=com_vertical\&parentid $=74$, http://sampark.iiit.ac.in/

[20] Vishal Goyal \& Gurpreet Singh Lehal, (2009) “Advances in Machine Translation Systems", National Open Access Journal, Volume 9, ISSN 1930-2940 http://www.languageinindia.

[21] Hemant Darabari, (1999) "Computer Assisted Translation System- An Indian Perspective", in proceedings of MT Summit VII, Thialand

[22] Sanjay Chatterji, Devshri Roy, Sudeshna Sarkar \& Anupam Basu, (2009) "A Hybrid Approach for Bengali to Hindi Machine Translation", In proceedings of ICON2009, 7th International Conference on Natural Language Processing, pp. 83-91.

[23] Sanjay Chatterji, Praveen Sonare, Sudeshna Sarkar \& Anupam Basu, (2011) "Lattice Based Lexical Transfer in Bengali Hindi Machine Translation Framework", in Proceedings of ICON- 2011: 9th International Conference on Natural Language Processing, Macmillan Publishers, India.

[24] S. Bandyopadhyay, (2004) "ANUBAAD - The Translator from English to Indian Languages", in proceedings of the VIIth State Science and Technology Congress. Calcutta. India. pp. 43-51

[25] Kommaluri Vijayanand, Sirajul Islam Choudhury \& Pranab Ratna "VAASAANUBAADA -Automatic Machine Translation of Bilingual Bengali-Assamese News Texts", in proceedings of Language Engineering Conference-2002, Hyderabad, India OIEEE Computer Society.

[26] R. Mahesh K. Sinha \& Anil Thakur, (2005) "Machine Translation of Bi-lingual Hindi-English (Hinglish) Text", in proceedings of 10th Machine Translation Summit organized by Asia-Pacific Association for Machine Translation (AAMT), Phuket, Thailand

[27] R. Ananthakrishnan, Jayprasad Hegde, Pushpak Bhattacharyya, Ritesh Shah \& M. Sasikumar, (2008) "Simple Syntactic and Morphological Processing Can Help English-Hindi Statistical Machine Translation", in proceedings of International Joint Conference on NLP (IJCNLP08), Hyderabad, India.

[28] Akshar Bharti, Chaitanya Vineet, Amba P. Kulkarni \& Rajiv Sangal, (2001) "ANUSAARAKA: overcoming the language barrier in India", published in Anuvad: approaches to Translation

[29] Akshar Bharti, Chaitanya Vineet, Amba P. Kulkarni \& Rajiv Sangal, (1997) "ANUSAARAKA: Machine Translation in stages', Vivek, a quarterly in Artificial Intelligence, Vol. 10, No. 3, NCST Mumbai, pp. 22-25

[30] G. S. Josan \& G. S. Lehal, (2008) "A Punjabi to Hindi Machine Translation System", in proceedings of COLING-2008: Companion volume: Posters and Demonstrations, Manchester, UK, pp. 157-160.

[31] Sugata Sanyal \& Rajdeep Borgohain, (2013) "Machine Translation Systems in India", Cornell University Library, arxiv.org/ftp/arxiv/papers/1304/1304.7728.pdf
[32] Gurpreet Singh Josan \& Jagroop Kaur, (2011) "Punjabi To Hindi Statistical Machine Transliteration", International Journal of Information Technology and Knowledge Management ,Volume 4, No. 2, pp. 459-463.

[33] Vishal Goyal \& Gurpreet Singh Lehal, (2011) "Hindi to Punjabi Machine Translation System", in proceedings of the ACL-HLT 2011 System Demonstrations, pages 1-6, Portland, Oregon, USA, 21 June 2011.

[34] Ananthakrishnan R, Kavitha M, Jayprasad J Hegde, Chandra Shekhar, Ritesh Shah, Sawani Bade \& Sasikumar M, (2006) "MaTra: A Practical Approach to Fully-Automatic Indicative English-Hindi Machine Translation", in proceedings of the first national symposium on Modelling and shallow parsing of Indian languages (MSPIL-06) organized by IIT Bambay, 202.141.152.9/clir/papers/matra_mspil06.pdf

[35] S. Mohanty \& R. C. Balabantaray, (2004) "English to Oriya Translation System (OMTrans)"cs.pitt.edu/chang/cpol/c087.pdf

[36] Antony P. J., (2013) "Machine Translation Approaches and Survey for Indian Languages", International journal of Computational Linguistics and Chinese Language Processing Vol. 18, No. 1, pp. 47-78.

[37] Ananthakrishnan R, Kavitha M, Jayprasad J Hegde, Chandra Shekhar, Ritesh Shah, Sawani Bade \& Sasikumar M., (2006) "MaTra: A Practical Approach to Fully- Automatic Indicative English-Hindi Machine Translation", In the proceedings of MSPIL-06.

[38] Latha R. Nair \& David Peter S., (2012) "Machine Translation Systems for Indian Languages", International Journal of Computer Applications (0975 -8887) Volume 39-No.1

[39] Sanjay Kumar Dwivedi \& Pramod Premdas Sukhadeve, (2010) "Machine Translation System in Indian Perspectives", Journal of Computer Science 6 (10): 1082-1087, ISSN 1549-3636, (C2010 Science

[40] R.M.K. Sinha \& A. Jain, (2002) "AnglaHindi: An English to Hindi Machine-Aided Translation System", International Conference AMTA(Association of Machine Translation in the Americas)

[41] Ankit Kumar Srivastava, Rejwanul Haque, Sudip Kumar Naskar \& Andy Way, (2008) "The MATREX (Machine Translation using Example): The DCU Machine Translation System for ICON 2008", in Proceedings of ICON-2008: 6th International Conference on Natural Language Processing, Macmillan Publishers, India, http://ltrc.iiit.ac.in/proceedings/ICON-2008.

[42] Yanjun Ma, John Tinsley, Hany Hassan, Jinhua Du \& Andy Way, (2008) "Exploiting Alignment Techniques in MATREX: the DCU Machine Translation System for IWSLT 2008', in proceedings of IWSLT 2008, Hawaii, USA

[43] Lucian Vlad Lita , Monica Rogati and Alon Lavie. (2005), "BLANC: Learning Evaluation Metrics for MT", Vancouver.

[44] Snover, M. and Dorr, B. (2006). A study of translation edit rate with targeted human annotation. In AMTA 2006: Proceedings of the 7th Conference of the Association for Machine Translation in the Americas. 
[45] Xingyi Song and Trevor C. (2011):,"Regression and Ranking based Optimisation for Sentence Level Machine Translation Evaluation", Proceedings of the 6th Workshop on Statistical Machine Translation,(pp. 123129).

[46] Boxing Chen and Roland Kuhn. (2011): "AMBER: A Modified BLEU, Enhanced Ranking Metric", Proceedings of the 6th Workshop on Statistical Machine Translation, pp. 71-77.

[47] Aaron L. F. HAN, Derek F. WONG and Lidia S. CHAO. (2012), "LEPOR: A Robust Evaluation Metric for Machine Translation with Augmented Factors", Proceedings of COLING, (pp. 441-450).

[48] Boxing Chen, Roland Kuhn and Samuel Larkin (2012): "PORT : a Precision-Order-Recall MT Evaluation Metric for Tuning", Proceedings of the 50th Annual Meeting of the Association for Computational Linguistics, (pp. 930939).
[49] Ankush Gupta, Sriram Venkatapathy and Rajeev Sangal, "METEOR-Hindi: Automatic MT Evaluation Metric for Hindi as a Target Language", Proceedings of ICON2010:8th International conference on Natural language processing, Macmillan Publishers, India.

[50] Aditi Kalyani , Hemant Kumud, Shashi Pal Singh , Ajai Kumar , Hemant Darbari, "Evaluation and Ranking of Machine Translated Output in Hindi Language using Precision and Recall Oriented Metrics", International Journal of Advanced Computer Research ,Volume-4 Number-1 Issue-14 March-2014.

[51] Aditi Kalyani, Hemant Kumud, Shashi Pal Singh, Ajai Kumar, "Assessing the Quality of MT Systems for Hindi to English Translation", IJCA, Volume 89 -No 15, March 2014. 